\section{Category}

Metal-Catalyzed Asymmetric

Synthesis and

Stereoselective

Reactions

\section{Key words}

\section{silver}

amino phosphine ligands

$\alpha, \beta$-diamino esters

P.-L. SHAO, J.-Y. LIAO, Y. A. HO, Y. ZHAO* (NATIONAL UNIVERSITY OF SINGAPORE, SINGAPORE)

Highly Diastereo- and Enantioselective Silver-Catalyzed Double [3+2] Cyclization of $\alpha$-Imino Esters with

Isocyanoacetate

Angew. Chem. Int. Ed. 2014, 53, 5435-5439.

\title{
Silver-Catalyzed [3+2] Cyclization of $\alpha$-Imino Esters with Isocyanoacetate
}

Significance: The authors present a double [3+2] cyclization of $\alpha$-amino esters with isocyanates to produce highly functionalized oxazole-imidazoles. Therefore, a silver oxide quinine derived amino phosphine ligand was used. For the pioneering work regarding isocyanates using a gold catalyst, see: Y. Ito, M. Sawamura, T. Hayashi J. Am. Chem. Soc. 1986, 108, 6405-6406.

SYNFACTS Contributors: Hisashi Yamamoto, Biplab Maji Synfacts 2014, 10(8), 0846 Published online: 18.07.2014 Dol: 10.1055/s-0034-1378419; Reg-No.: H07914SF
Comment: Kinetic studies identified two cyclization processes to be step-wise. The intermediates, mono-[3+2] cyclization products, were isolated. The products can be hydrolyzed to yield functionalized $\alpha, \beta$-diamino esters. 